\title{
COMET SCHWASSMANN-WACHMANN 3 (1930 VI)
}

N. A. BELYAEV and S. D. SHAPOREV

Institute of Theoretical Astronomy, Leningrad, U.S.S.R.

The definitive orbit of comet 1930 VI basing on 190 observations has been derived. Investigation of the comet orbit evolution for the time span of $200 \mathrm{yr}$ indicated that the 1882 approach $\left(t_{\mathrm{appr}}=1882\right.$ Oct. $\left.22.559 ; \Delta_{\min }=0.0057 \mathrm{AU}\right)$ of the comet to Jupiter resulted in considerable element transformations. The perihelion and aphelion distances reduced from 4.1 AU to $1.2 \mathrm{AU}$ and from 12.2 AU to $5.2 \mathrm{AU}$, respectively, whereas the period of revolution also underwent a decrease from $23.3 \mathrm{yr}$ to $5.8 \mathrm{yr}$. The next return of the comet to the perihelion is to be expected in 1974 ( $T=1974$ March, 17.475). 